\title{
O panorama actual das industrias culturais galegas: as políticas públicas culturais
}

\author{
Current Panorama of Galician Cutural Industries: \\ Cultural Public Politics
}

\author{
Marta GonzÁLEz SuÁREZ \\ Universidad Nacional de Educación a Distancia \\ Universidad Carlos III \\ martagonsuarez@gmail.com
}

[recibido 29/10/2014, aceptado 26/01/2015]

\begin{abstract}
RESUMO
Este traballo aborda desde unha perspectiva de análise socio-política o contexto anterior á autonomía de Galiza e a evolución inmediata das políticas públicas galegas unha vez instaurado o Estado autonómico co obxectivo de comprender a situación presente da nosa cultura. Ao mesmo tempo expón con detalle o actual concepto de industrias culturais e fai un repaso das estratexias desenvolvidas na nosa comunidade por parte do sector como mecanismo para garantir a viabilidade e autonomía dos proxectos de contido cultural.
\end{abstract}

PALABRAS CHAVE: Industria cultural galega, políticas públicas culturais, actual contexto cultural de Galiza, iniciativas culturais galegas.

\section{RESUMEN}

Este trabajo aborda desde una perspectiva de análisis socio-político el contexto anterior a la autonomía de Galicia y la evolución inmediata de las políticas públicas gallegas una vez instaurado el Estado autonómico con el objetivo de comprender la situación presente de nuestra cultura. Al mismo tiempo expone con detalle el actual concepto de industrias culturales y hace un repaso de las estrategias desarrolladas en nuestra comunidad por parte del sector como mecanismo para garantizar la viabilidad y la autonomía de los proyectos culturales.

PALABRAS CLAVE: Industria cultural gallega, políticas públicas culturales, actual contexto cultural de Galicia, iniciativas culturales gallegas.

\section{ABSTRACT}

Based on a socio-political analysis perspective, this work is about the state before the autonomy of Galicia and the immediate evolution of Galician public politics once its autonomy was set up, with the aim of understanding the current situation of our culture. At the same time, it exposes in detail the current concept of cultural industries and it reviews the strategies developed by this sector in our autonomous region as a mechanism to guarantee the cultural projects' viability and autonomy.

KEY WORDS: Galician cultural industry, cultural public politics, current cultural context of Galicia, Galician cultural initiatives.

GonZÁlez SuÁrez, M. (2015): “O panorama actual das industrias culturais galegas: as políticas públicas culturais”, Madrygal (Madr.), 18, Núm. Especial: 555-568.

SUMARIO: 1. Introdución. 2. Que son as industrias culturais? 2.1. Cara a un concepto de industrias culturais. 2.2. Elementos definidores das actuais industrias culturais. 3. Precedentes socio-políticos do contexto cultural galego actual. 4. Primeiros pasos cara á construción dunha estrutura cultural en Galiza. 5. A aparición das industrias culturais na comunidade galega. 6. O impacto das industrias culturais en Galiza. 7. Últimas iniciativas da industria galega. 8. Referencias bibliográficas. 


\section{INTRODUCIÓN}

Este traballo pretende facer unha achega sobre a situación actual na que se encontran as industrias culturais galegas, analizadas nun contexto de crise económica por todos coñecido, mais desenvolvidas sobre a base duns precedentes socio-políticos que contribúen en gran medida a que o estado actual da cultura galega sexa o que é. A crise proxecta unha serie de condicionantes de impacto indubidábel, mais a propia idiosincrasia da sociedade de Galiza, a influencia de factores demográficos e o estado previo do tecido industrial determinan igualmente a evolución deste sector, tan sensíbel ás flutuacións e continxencias do contorno.

\section{QUE SON AS INDUSTRIAS CULTU- RAIS?}

Calquera mínimo achegamento á materia das industrias culturais esixe partir dunha, aínda que sexa breve, definición do concepto. A este respecto, hai unha serie de elementos cuxa incorporación á noción de industrias culturais está solidamente aceptada por parte dos autores e profesionais, mais, a pesar desta consensuada unanimidade, o que non está tan definido son os propios límites do alcance do termo, malia o aparente paradoxo que isto encerra. Trataremos de abordar estas cuestións de forma condensada nas seguintes liñas.

\subsection{CARA A UN CONCEPTO DE INDUS- TRIAS CULTURAIS}

O termo "industrias culturais" comezou a ser empregado nos anos corenta do século pasado no seo da escola de Frankfurt ${ }^{1}$. Os filósofos Adorno e Horkheimer usan por vez primeira este concepto para aludir ás mudanzas que se estaban a producir cara a un tratamento mercantilista das creacións culturais, en gran parte potenciado polo feito de que xa a tecnoloxía do momento comezaba a posibilitar as reproducións masivas dalgunhas destas creacións pensando nun público de masas. Sen lugar a dúbidas, nesta noción advírtense apreciacións negativas sobre a evolución social da materia cultural, e non encubría o claro temor de que a propia sociedade estivese a propiciar a deturpación deste preciado ben. No entanto, o termo non se consolida até ben avanzado o último terzo do século e nesta primeira evolución a valoración dos beneficios derivados do xurdimento dunha auténtica industria da cultura, especialmente potenciados por parte dalgunhas nacións referentes na produción de espectáculos e produtos culturais, supera os posíbeis receos cara a unha acollida sen pexas destes procesos de industrialización do sector. Zallo define as industrias culturais como:

un conxunto de ramas, segmentos e actividades auxiliares industriais produtoras e distribuidoras de mercadorías con contidos simbólicos, concibidas por un traballo creativo, organizadas por un capital que se valoriza e destinadas finalmente aos mercados de consumo cunha función de reprodución ideolóxica e social. (Zallo 1988: 26; apud Fernández Freixanes 2010: 18)

En semellantes termos son definidas por Getino como:

empresas de producción y comercialización de bienes y servicios culturales, destinados a su difusión y comercialización en amplios sectores de la población. Su función es la de producir

\footnotetext{
${ }^{1}$ Considero oportuno facer unha breve referencia á orixe e obxectivos desta coñecida escola. De acordo con Blanca Muñoz (en Reyes (dir.) 2009), esta corrente de estudos xurdiu en Alemaña como unha consecuencia dos intensos movementos e correntes ideolóxicas de base social que se tiñan orixinado en Europa a partir dos anos 20. A actividade da escola desenvolvíase principalmente en torno ao Instituto de Investigación Social, centrado na produción de teorías sobre as condicións sociais e históricas dunha sociedade burguesa-capitalista como a que se estaba a consolidar naquela época, desde a proxección de correntes ideolóxicas marxistas. Tomando en conta a amplitude do seu campo de traballo, non é extraño que a evolución da propia cultura e o seu tratamento social fose tamén un dos seus focos de estudo.
} 
("fabricar") mercancías o servicios de carácter cultural (libros, discos, películas, emisiones de radio, programas de TV, etc.) destinadas específicamente a difundir y reproducir en términos de prototipo o de serialización determinados contenidos simbólicos (obras literarias, obras musicales, obras cinematográficas, obras televisivas, información, etc.) ${ }^{2}$. (Getino 2001)

Pola súa parte, no estudo sobre industrias culturais elaborado ao amparo dun proxecto de investigación sobre esta materia aprobado na Conferencia Xeral da Unesco de 1978,

se estima, en general, que existe una industria cultural cuando los bienes y servicios culturales se producen, reproducen, conservan y difunden según criterios industriales y comerciales, es decir, en serie y aplicando una estrategia de tipo económico, en vez de perseguir una finalidad de desarrollo cultural ${ }^{3}$.

En épocas máis recentes o contido destas definicións no seo da Unesco perderon en parte ese matiz de crítica encuberta sobre os aspectos negativos que implica o tratamento indutrial da cultura. Así, entre os documentos que a institución elabora como guías das liñas estratéxicas a seguir en áreas específicas, a Guía para el desarrollo de las industrias culturales y creativas, confeccionada ao aveiro das estadísticas culturais da Unesco en 2009, define as industrias culturais como:
Aquellos sectores de actividad organizada que tienen como objeto principal la producción o la reproducción, la promoción, la difusión y/o la comercialización de bienes, servicios y actividades de contenido cultural, artístico o patrimonial $^{4}$.

A cuestión que fica por acoutar no tocante ás indutrias culturais, alén de acordar unha definición doutrinal unánime, é determinar qué materias se entenden incluídas neste amplo campo de actividade, o que até certo punto implica adoptar unha posición concreta en relación ao concepto de cultura que se emprega de forma inherente ao propio termo. A este respecto cómpre indicar que a tendencia observada nas ramas de estudo alleas á antropoloxía cultural é a de recorrer a unha dicotomía terminolóxica cando se aborda a cultura como obxecto de traballo. En ocasións acoden a un concepto de base antropolóxica, o que redunda na adopción dunha postura ampla e relativa no uso e aplicacións da cultura; e outras veces empregan unha noción máis restrinxida, que toma o termo cultura desde a perpectiva das súas manifestacións artístico-culturais, concepción que ten a súa orixe nas correntes de pensamento da Ilustración e que aínda a día de hoxe segue a proxectar a súa influencia sobre determinadas categorías terminolóxicas cuxo uso, malia a evolución científica das ramas de

2 “empresas de produción e comercialización de bens e servizos culturais, destinados á súa difusión e comercialización en amplos sectores da poboación, a súa función é a de producir ("fabricar") mercadorías ou servizos de carácter cultural (libros, discos, películas, emisións de radio, programas de TV, etc.) destinadas especificamente a difundir e reproducir en termos de prototipo ou de serialización determinados contidos simbólicos (obras literarias, obras musicais, obras cinematográficas, obras televisivas, información, etc.)" (tradución propia).

3 "estímase, en xeral, que existe unha industria cultural cando os bens e servizos culturais se producen, reproducen, conservan e difunden segundo criterios industriais e comerciais, é dicir, en serie e aplicando unha estratexia de tipo económico, en vez de perseguiren unha finalidade de desenvolvemento cultural" (tradución propia). O estudo deu como resultado a publicación da obra Industrias culturales: el futuro de la cultura en juego, obra de onde tomamos a definición (VV.AA. 1982: 21), se ben a Unesco remarcou nunha nota ao prólogo que as opinións vertidas neste traballo pertencen aos seus autores e non reflicten necesariamente a postura da Unesco sobre esta materia.

4 "Aqueles sectores de actividade organizada que teñen como obxecto principal a produción ou a reprodución, a promoción, a difusión e/ou a comercialización de bens, servizos e actividades de contido cultural, artístico ou patrimonial" (tradución propia). Véxase: http://www.unesco.org/new/es/culture/themes/ cultural-diversity/diversity-of-cultural-expressions/tools/policy-guide/como-usar-esta-guia/sobre-definiciones-que-se-entiende-por-industria s-culturales-y-creativas/ (última consulta: 28/10/2014). 
estudo propias, continúa vixente. De feito, a propia división estrutural da meirande parte dos ministerios de cultura dos países europeos responden a esta noción ilustrada e inclúen no apartado 'Cultura' todas as manifestacións da arte e creacións produto do intelecto do home. Polo que respecta á definición das industrias culturais, o Ministerio de Cultura do Goberno de España enumera unha serie de sectores de actividade que se deben entender incluídos nelas: "Las industrias culturales incluyen generalmente los sectores editorial, multimedia, audiovisual, fonográfico, producciones cinematográficas, artesanía y diseño"5.

\subsection{ELEMENTOS DEFINIDORES DAS ACTUAIS INDUSTRIAS CULTURAIS}

Os elementos comúns en todas estas definicións poñen de manifesto algunhas das características unanimemente aceptadas en torno ao tema das industrias culturais, que nós trataremos de expor de forma sistemática deseguido.

\section{Público de masas}

As industrias culturais abordan o proceso de creación de bens culturais desde unha perspectiva baseada na rendibilidade económica obtida pola súa comercialización. Isto fai que se acade unha maior ganancia coa presenza dun público numeroso ou dun gran número de consumidores. En gran medida, o propio concepto de industrias culturais precisa para a súa construción doutrinal a evolución paralela dun estado tecnolóxico que posibilite a produción seriada das creacións artístico-culturais.

Este feito bate directamente coa concepción esencial tradicional das creacións artísticas, un de cuxos elementos definidores é precisamente o carácter único, persoal, intransferíbel e irrepetíbel da súa elaboración. En realidade, a meirande parte das creacións culturais que coñecemos continúan a conservar esta nota esencial que caracteriza a súa exclusividade e unicidade; mais son os modelos de consumo os que están a mudar. A execución dunha obra de teatro é única en cada representación, por iso o que se procura é aumentar o número de espectadores e a permanencia da obra en cartaz. O mesmo acontece cun concerto, unha representación de danza, etc. Fóra dalgúns supostos en que a propia técnica artística posibilita unha reprodución infinita (pensemos na fotografía, nunha litografía, nunha gravación sonora ou nun libro), as restantes manifestacións da arte conservan este atributo da exclusividade (pintura, debuxo, escultura). Nestes casos a procura da rendibilidade acádase por outras vías: ben expoñendo a obra a un público numeroso que aboe a entrada ao recinto, ben valorando esa peza na medida da súa exclusividade e carácter único mediante a súa venda nunha feira de arte. Porén, no tocante a este último exemplo, é preciso sinalar que as artes plásticas que empregan técnicas tradicionais son as que continúan un camiño máis afastado da tendencia que hoxe se advirte nas prácticas das industrias culturais, precisamente polo motivo antedito de seren menos susceptíbeis dunha produción seriada masiva.

Neste eido, a resposta do sector das industrias culturais resólvese mediate a construción dun artificio: o mercado da arte, terreo tradicionalmente revestido dun halo de quasemisticismo e sofisticación erroneamente adxudicado en exclusiva a coleccionistas adiñeirados e marchantes do xénero. Por fortuna, esta barreira irreal que parece circundar o mundo das compravendas de obras de arte está a experimentar unha apertura positiva cara a un público consumidor cada vez máis novo que se aventura con adquisicións máis accesíbeis; de forma que os mecanismos de achegamento ao sector das artes plásticas, quer mediante actividades expositivas e de difusión, quer a través da extensión e progresiva normalización das feiras de arte, constitúen o paradigma das industrias culturais nestas disciplinas en particular, respectando así o seu carácter único e irrepetíbel.

\footnotetext{
${ }^{5}$ De acordo co sitio web do Ministerio de Cultura: http://www.mcu.es/emprendedores/ConoceElSector. html (última consulta: 20/10/2014).
} 


\section{Proceso de industrialización}

Se ben é certo que a propia idea de industrialización deriva do concepto mesmo de industrias culturais, a proxección que se pretende atinxir con este termo merece unha breve aclaración. Facer mención a un proceso semellante nun contexto aparentemente tan alleo ao sector de actividade que lle é propio (referímonos ás idustrias transformadoras do sector secundario dentro da tripartición en que tradicionalmente se dividen os ciclos de actividade económica) pretende engadir á noción de arte e cultura un valor de carga económica que poña de manifesto, non só a súa potencial rendibilidade como sector capaz de xerar beneficios cuantificábeis, mais tamén a posibilidade de que os mecanismos de creación empregados até o momento neste campo poden evolucionar, da mesma forma que o fixeron noutras materias, para se tornar máis eficaces, produtivos e explotábeis. Empregar a palabra industria evidencia, ademais, unha aproximación aos bens e produtos culturais que rebaixa en certa medida, sen negala por completo, as connotacións intanxíbeis e os valores subxectivos e inmateriais asociados a esta clase de creacións.

A industrialización implica unha mudanza de perspectiva no tratamento dos procesos creativos e nos cauces de consumo e comercialización dos bens e produtos culturais, de tal maneira que se pretende respectar a súa especial natureza mais acoplándoa a uns cauces económicos eficaces que garantan unha produción continuada e sostíbel, unha autonomía financeira, unha oferta variada e permanente, evitando así, na medida do posíbel, a improvisación na oferta comercial destes bens, a confianza en golpes de sorte ou nos impulsos creativos dos artistas baseados na inspiración, coa conseguinte inconstancia e incertidume derivada. A vocación última é a de avanzar cara a unha progresiva profesionalización destes procesos, entendidos desde unha perpectiva global que abrangue a totalidade dos pasos necesarios para que un ben cultural chegue a un consumidor final. Isto implica contemplar tanto o propio proceso de creación como controlar os cauces de difusión e posíbel comercialización deses bens.

\section{Márketing cultural}

En liña con algunhas das ideas apuntadas no parágrafo precedente, a incursión neste terreo de actividade da connotación económica implícita no termo márketing enténdese hoxe como unha disciplina de mercado indisociábel das industrias culturais. O propio proceso de industrialización do que vimos de falar explica como a incorporación das técnicas de márketing neste eido, aplicadas fundamentalmente nas últimas etapas do proceso, isto é, nas fases de difusión e comercialización, contribúen a fornecer a construción dunha verdadeira industria da cultura.

No entanto, é innegábel que o emprego destes mecanismos, de corte claramente mercantilista, non agochan o claro interese de acentuar o aspecto máis comercial dos sistemas de consumo e comunicación dos bens e produtos culturais; talvez non tanto na creación mesma, na que se continúa a respectar a súa esencia artístico-cultural, mais si dun modo evidente en todo aquilo que contorna o cauce de saída natural desa creación, desde os mecanismos de comunicación e publicidade até as vías de venda e distribución.

\section{Emprego das novas tecnoloxías}

$\mathrm{O}$ termo de industrias culturais, como xa vimos, non é recente, mais a actual definición do sector experimentou unha evolución conceptual en que a incorporación das novas tecnoloxías vén a ser a día de hoxe un elemento estrutural imprescindíbel. Nos últimos tempos as industrias culturais deron un salto cualitativo cara a unha ansiada profesionalización que, no contexto actual de avance tecnolóxico e de desenvolvemento das comunicacións, non podía permanecer á marxe das TIC. A coincidencia temporal destes últimos pasos cara á consolidación da industria coa incorporación de técnicas vindas doutras disciplinas económicas, como o xa mencionado márketing, pódese mesmo entender como unha consecución lóxica das sinerxias positivas derivadas da relación destes campos de actividade: a comunicación e a mercadotecnia, hoxe en día consideradas case como dúas caras dunha mesma moeda. 
Con certeza, o recurso ás novas tecnoloxías acompaña as industrias culturais en todas as súas fases, até o punto de seren moitas veces obxecto das propias creacións artísticas, que utilizan estas vías como cauce de expresión ou as converten en idea central das obras creadas. En calquera caso, o interesante no que atinxe á construción dunha industria é que, se cabe, neste eido particularmente sensíbel tanto ás flutuacións económicas como ás variacións de financiamento por parte das políticas públicas, a incorporación das tecnoloxías serve para avanzar cara a unha maior autonomía na elaboración e xestión de proxectos culturais, pois contribúen a democratizar e popularizar as vías de comunicación e permiten chegar ao público-consumidor que é preciso en cada momento e lugar.

\section{Servizos derivados}

Por último, debemos salientar que o concepto actual de industrias culturais, tirado dun contexto que considera os procesos creativos e de consumo cultural como un todo, parte dunha visión globalizada en que se toman en consideración todos os labores e servizos relacionados directa ou indirectamente coa creación, produción, difusión, distribución e comercialización deste tipo de bens. Neste sentido, a proxección das industrias culturais como campo de actividade capaz de xerar emprego e riqueza estende os seus límites até abranguer toda clase de profesións vinculadas cos labores da cultura, desde o traballo dun artista ao servizo dunha persoa que atende o despacho de billetes dun teatro. Os puntos que expuxemos anteriormente evidencian o tratamento profesionalizado que se está a dar no campo da cultura. A xuntanza e interrelación de todos estes aspectos que configuran as chamadas industrias da cultura xustificarían, na miña opinión, que se falase con maior propiedade de empresas culturais ou da empresarialización deste sector, para evitarmos así connotacións asociadas ao termo industria que nos remiten á actividade do sector secundario, un sector de transformación intermedio, non directamente relacionado cun público ou consumidor inmediato. As referencias á empresa poderían igualmente recoller esa vontade de representar os avances globais no tratamento dos bens e servizos culturais, vistos como un conxunto de fases interrelacionadas chamadas a formar parte dunha cadea produtiva cuxo fin é a difusión e coñecemento das producións artístico-culturais por un público final. A pesar disto, o concepto de industrias culturais está abondo arraigado como para ser susceptíbel de mudanza e por iso debemos comprender o verdadeiro alcance que ten.

Os elementos que acabamos de tratar poñen de manifesto a complexidade que caracteriza este campo de acción, que participa, por outro lado, das mesmas correntes de actualización e modernización presentes noutras ramas de actividade, aínda que até o de agora non teña sido un eido produtivo obxecto dunha especial consideración nin por parte do mercado, nin por parte das políticas públicas. Esta tendencia marxinadora está a mudar nos últimos tempos e os avances producidos cara a unha profesionalización efectiva son evidentes.

Non podo fechar este apartado sen facer referencia ao termo industrias recreativas ou do entretemento. $\mathrm{O}$ emprego desta idea manifesta no seu propio enunciado a ausencia dunha auténtica preocupación polo tratamento das creacións artístico-culturais como tales, senón a conversión destes bens en verdadeiros obxectos de negocio capaces de producir riqueza económica. Este é, por outra parte, un termo máis frecuente no contexto norteamericano de concepción dos bens e servizos culturais, onde os beneficios obtidos da súa industria cinematográfica e do espectáculo chegan a superar aos xerados por outros sectores de actividade. A salvagarda da natureza cultural dos bens é unha posición máis europeísta, e a mención ás industrias culturais respecta precisamente esta postura proteccionista cara á especial cualidade destas creacións. Falar de industria non implica necesariamente mercantilizar por completo esta clase de bens.

\section{PRECEDENTES SOCIO-POLÍTICOS DO CONTEXTO CULTURAL GALEGO ACTUAL}

Sen ánimo de nos deter pormenorizadamente nalgúns aspectos histórico-políticos que anteceden e explican o actual estado da cultura 
en Galiza, convén polo menos mencionalos para ofrecer un marco adecuado que permita unha comprensión global do panorama dasnosas industrias.

Neste punto convén ter presente a ausencia en Galiza dunha autonomía política sostida durante un tempo demorado que permitise introducir cambios na idiosincrasia da nosa sociedade e tomar consciencia da nosa capacidade de produción, mudanza de hábitos ou renovación do tecido industrial en que se baseaba a nosa economía. O período da ditadura marcou unha época de represión expresiva que atacou un dos alicerces sobre os que se sostén a identidade cultural galega: a lingua. Non foi até a chegada do estado autonómico, tras o estabelecemento dun estado español constitucional e o recoñecemento a Galiza do seu carácter de comunidade histórica, cando esta situación comenzou a mudar de forma progresiva. $\mathrm{O}$ artigo 32 do noso Estatuto de Autonomía, aprobado en 1981, dispón:

Correspóndelle á Comunidade Autónoma a defensa e promoción dos valores culturais do pobo galego. Con tal finalidade, e mediante lei do Parlamento, constituirase un Fondo Cultural Galego e o Consello da Cultura Galega.

A partir deste momento a asunción dunha responsabilidade para coa cultura galega por parte das institucións que integraron o goberno autonómico, a través tamén destes organismos creados ad hoc cunha clara finalidade de defensa cultural, comezou a producir efectos positivos, especialmente nas actuacións centradas na recuperación da lingua.

A esta ausencia de tradición de autonomía política súmanse outros factores igual de determinantes. A economía galega estaba baseada no sector primario, fundamentalmente gandeiría e pesca. Nesta situación, un salto cualitativo cara ao sector terciario é particularmente difícil e lento, porque precisa de mudar moitos hábitos produtivos e, sobre todo, de consumo. De feito, non é até 1988 que o sector servizos supera ao sector agrario en ocupación ${ }^{6}$; mais incluso na década dos 90 o peso do sector primario na economía galega seguía a duplicar a media española ${ }^{7}$. Porén, a autonomía acabada de estrear supuxo un cambio patente na adopción de novos modelos económicos que viñeron a mudar de raíz o sistema preexistente, de forma que a inclinación do peso da economía cara ao sector servizos foi paulatino mais imparábel.

Cómpre engadir a referencia a outros factores igualmente relevantes na configuración deste contexto social previo, como son a estrutura demográfica da sociedade galega, os patróns de asentamento da poboación e a influencia da orografía. Con certeza, o avellentamento predominante na nosa sociedade, particularmente acusado nas provincias de Ourense e Lugo, supón un punto de partida adverso á introdución de cambios drásticos nos modelos económicos e á renovación de pautas de consumo en que se vaian asentando hábitos culturais. A isto súmase a distribución dispersa da poboación en todo o territorio da comunidade, o que contribúe a dificultar a extensión de novos costumes, cuxo foco de arraigamento adoita ser o núcleo urbano. Por último, convén ter presente o relativo illamento ao que está sometida a nosa comunidade, onde a complexa orografía do terreo contribúe a pexar a comunicación tanto ad intra como ad extra en relación co resto do Estado.

Sen lugar a dúbidas o contexto dunha sociedade de base agraria e asentada no medio rural, que continuaba a practicar en moitos casos unha economía de autoconsumo no fogar, xunto con esoutros factores que favorecen o retardo na mudanza de costumes, explica facilmente que Galiza fose unha rexión onde os cambios no sistema económico e, con el, nos

${ }^{6}$ INE. Enquisa de poboación activa. Resumos comparativos por CC.AA. 1976 T III-1995 T IV (apud Lage, Losada e Gómez 2012: 117): http://www.ine.es/jaxi/tabla.do?path=/t22/e308/meto 02/pae/px/10/\&file $=02002$. $p x \&$ type $=$ pcaxis.

\footnotetext{
${ }^{7}$ Lage, Losada y Gómez (2012: 119).
} 
usos e hábitos culturais, se fixesen agardar máis do desexábel. Aínda así, o influxo positivo e construtivo da man dun modelo autonómico que recoñecía a esta comunidade unha plena capacidade de autogoberno en eidos tan relevantes como o cultural supuxo un pulo que, con maior ou menor acerto, as primeiras institucións galegas de seu quixeron aproveitar.

\section{PRIMEIROS PASOS CARA Á CONS- TRUCIÓN DUNHA ESTRUTURA CUL- TURAL EN GALIZA}

As mudanzas introducidas nos primeiros tempos do goberno autonómico estiveron centradas en tres liñas fundamentais: a lingua galega, o fomento das prácticas culturais propias e o impulso do turismo como fonte de beneficios económicos, das que a recuperación da lingua mereceu unha destacada atención. Non debemos esquecer que o Estatuto de Autonomía galego prevía, ademais, a creación dun organismo centrado na salvagarda da nosa cultura: o Consello da Cultura Galega. O preámbulo da lei 8/1983, de 8 de xullo, pola que se crea esta institución, expón algunhas ideas fundamentais para comprender a vocación coa que nace o Consello:

As áreas de acción do Consello son moi variadas. A acción cultural atinxe ás múltiples facetas da vida do home e das sociedades. Por iso, as leis das nacións e os tratados e convenios defenden, a un tempo, o dereito de todos a seren parceiros do cultivo do espírito, a asumilos seus valores vixentes, a gozar, xeración tras xeración, dos bens da memoria histórica e do acervo das creacións, a recibi-la benfeitoría do progreso das ciencias e das súas aplicacións e da protección e defensa de canto lles é propio nos campos da lingua, das letras e das artes. Un patrimonio cultural tan vizoso coma o que posúe e carácteriza a nosa nacionalidade e o programa, fondo e de alongados horizontes, que ten de ser desenrolado pola nosa Comunidade, requiren a formación dun órgano cualificado, tal como concibe o Estatuto.
Pola súa parte, o artigo $1^{\circ}$ da lei sinala que o Consello se crea "Coa finalidade de defender e promociona-los valores culturais do pobo galego, conforme co previsto no artigo 32 do Estatuto de autonomía de Galicia”.

Tocante ao tratamento da lingua galega, os primeiros pasos estiveron centrados no seu proceso de normalización e normativización, tanto por unha cuestión política de identidade como por unha necesidade social de dotar o idioma dun estatus propio. No campo das iniciativas culturais de difusión destaca a creación da Compañía de Radio Televisión de Galicia en 1985, da que se di na súa web oficial que "A misión primeira da Compañía é mellorar e normalizar o uso da nosa lingua oficial, o Galego, e promover a nosa cultura, a través da Televisión de Galicia (TVG) e da Radio Galega (RG)". Cómpre tamén mencionar o labor da Real Academia Galega que, se ben data de 1906, non tivo até o recoñecemento da cooficialidade do idioma galego na Constitución española plena liberdade de actuación e, de feito, vírase obrigada a alternar períodos de cese de actividade con outros de funcionamento clandestino. Desde a entrada do Estado autonómico, a Academia obtivo un respaldo pleno por parte das institucións públicas no desempeño da súa misión: "A Real Academia Galega é unha institución científica que ten como obxectivo fundamental o estudio da cultura galega e especialmente a ilustración, defensa e promoción do idioma galego"

De modo paralelo, os esforzos pola recuperación da lingua ían acompañados de iniciativas de fomento e dinamización de axentes culturais de base colectiva, como a creación de asociacións veciñais e a concesión de axudas para a realización de festexos populares e recuperación, ensino e coñecemento de prácticas e usos tradicionais, moitos deles acalados durante o período político precedente.

Por último, aínda que a súa efectividade se demorou até pasados algúns anos, o terceiro

\footnotetext{
${ }^{8}$ Artigo I dos actuais Estatutos da Real Academia Galega aprobados por Real Decreto 271/2000 de 25 de febreiro.
} 
punto de apoio das tácticas políticas en materia cultural do primeiro goberno autonómico centrouse no fomento do turismo, como un dos potenciais filóns do que tirar un substancial beneficio económico. Ben que o turismo é unha forma de achegamento indirecto á cultura, a estratexia empregada no seu momento baseouse fundamentalmente na recuperación do Camiño de Santiago, coa conseguinte construción de todo un discurso histórico-cultural que alicerzaba o impulso desta iniciativa. $\mathrm{O}$ Camiño de Santiago pasou a ser unha vía de coñecemento de toda a comunidade, da súa paisaxe e gastronomía, da súa historia, e un bo pretexto para dinamizar o tecido económico galego e atraer un cuantioso número de visitantes. A táctica posta en práctica polo goberno autonómico a este respecto foi a de potenciar separadamente a área de turismo e canalizar a actividade a través de Turgalicia, como Dirección Xeral de Turismo, e Xacobeo S.A., empresa pública dependente da Xunta de Galiza creada en 1991 con vistas ao Xacobeo'93, primeiro grande evento de transcendencia nesta liña de traballo que marcou un fito no desenvolvemento posterior das actuacións turísticoculturais por parte do goberno galego 9 .

\section{A APARICIÓN DAS INDUSTRIAS CULTURAIS NA COMUNIDADE GA- LEGA}

A creación dunha rede institucional sólida, sostida polos poderes públicos, contribúe a normalizar o exercicio da actividade cultural, a respaldala e a incentivar a súa profesionalización.
O xiro operado no seo da sociedade galega cara á incorporación das manifestacións culturais na base estrutural do tecido social requiriu dunha actividade permanente por parte de todos os organismos inplicados. A este respecto deben ser mencionados certos momentos de especial transcendencia no desenvolvemento posterior das liñas de traballo. Por exemplo, a fundación en 1984 do Centro Dramático Galego, dedicado á produción e distribución de espectáculos teatrais, ou a creación do IGAEM, Instituto Galego das Artes Escénicas e Musicais, en 1989, institucións que daban conta dunha procura consciente de solvencia e integridade no sector.

No entanto, durante máis de 25 anos de autonomía o concepto de industrias culturais non figurou no horizonte de prioridades estruturais no eido das políticas culturais. Se ben as decisións adoptadas até o momento evidenciaban unha clara preocupación por fortalecer as producións culturais propias e dotalas de entidade e autonomía, non existía unha consciencia plena da necesidade de trabar un verdadeiro tecido produtivo neste campo de actividade que tivese en conta a versatilidade da materia e a conveniencia de interrelacionar as distintas disciplinas artísticas e a multitude de axentes implicados nos procesos de creación e difusión cultural. De feito, a concesión de axudas, unha das principais vías de inxección de recursos no sector, funcionaba case como compartimentos estancos, outorgándose para unha creación en particular que non garantía, en absoluto, unha desexábel continuidade produtiva a medio ou longo prazo.

\footnotetext{
${ }^{9}$ A separación entre as áreas de Turismo e Cultura evidenciaba unha estratexia subxacente por parte do goberno autonómico, que quixo facer depender de partidas orzamentarias separadas o investimento nestes dous sectores, considerados fundamentais nos primeiros anos de actividade tras a estrea da nova autonomía. A denominación da Consellería de Turismo compartiu plantel coa área de Xuventude até 1993, tivo unha Consellería propia de 1994 a 1996 e a partir de 1997 integrouse na denominada Consellería de Cultura, Comunicación Social e Turismo. A mudanza operada neste ano puña de manifesto a íntima conexión no tratamento da materia cultural e a turística por parte dos poderes públicos, cunha clara proxección de rendibilidade económica e, ao tempo, evidenciaba a mingua orzamentaria aplicada ao fusionar estas partidas, no seo da cal a meirande parte era destinada a turismo. A asunción do goberno pola coalición bipartita do BNG e o PSOE en 2006 trouxo consigo un cambio na concepción desta distribución administrativa, pasando a constituír a Consellería de Cultura e Deportes, mudanza que durou o que este goberno de coalición, pois a fusión das materias de turismo e cultura recuperouse co novo goberno de Feijoo. A pretensión do bipartito, en palabras de Carlos Amoedo, ex-Secretario Xeral de Cultura era "desmarcarse dunha connotación demasiado mercantil da política cultural” (Lage, Losada e Gómez 2012: 123).
} 
Esta situación comenzou a mudar cando se produciu unha mudanza de cor política no goberno autonómico. A coalición de PSOE e BNG ocupou o poder entre 2006 e 2009, e unha das súas primeiras decisións afectou ao sector que agora nos ocupa. En primeiro lugar, escindiron a materia de turismo da de cultura, xurdindo a Consellería de Cultura e Deporte. Este foi tamén un período interesante no tocante á produción lexislativa de contido cultural: a Lei 17/2006, de 27 de decembro, do Libro e da Lectura, ou a Lei 9/2007, de 13 de xuño, de Subvención de Galiza, entre outras ${ }^{10}$. Mais o que supuxo un antes e un despois no tratamento das industrias culturais como tales na nosa comunidade foi a creción, por Lei 4/2008, da AGADIC, Axencia Galega das Industrias Culturais, que substituíu o anterior IGAEM, instituto que ficara até certo punto obsoleto por deixar á marxe unha parte importantísima da nosa produción cultural propia: as empresas do ámbito multimedia e audiovisual.

Coa AGADIC, non só a finalidade coa que se creou, mais tamén a súa propia denominación púñase de manifesto un cambio substancial no achegamento á materia cultural. A mudanza de perspectiva deixaba traslucir os primeiros pasos cara a un tratamento global do conxunto das manifestacións culturais e a progresiva toma de consciencia do seu potencial como fonte de riqueza e vía de dinamización da economía galega.O termo "industrias culturais" entra así de cheo no panorama institucional e a Axencia asume a responsabilidade de canalizar os recursos públicos investidos no sector co obxectivo primordial de xerar unha verdadeira industria da cultura. Con gran clarividencia, os principios que motivan a creación desta Axencia fican condensados no preámbulo da devandita lei:

No mundo contemporáneo, a cultura caracterízase por ser un ben social de carácter multidimensional: constitúe o elemento que mellor expresa as ideas e os valores nos que Galicia funda a súa entidade e identidade no contexto global, e ao tempo é un instrumento que cohesiona ao noso pobo, reforza as relacións entre a cidadanía, corrixe as desigualdades, integra os colectivos desfavorecidos e facilita a cooperación entre os pobos. (...) Mais a cultura é tamén un campo cada vez máis importante de desenvolvemento económico sustentable. O enfoque económico dos sectores culturais e creativos cobra unha paulatina importancia a medida que os seus produtos xeran un alto valor engadido e adquiren, pola súa singularidade, un alto potencial competitivo nos mercados. (...) O obxecto desta lei é a creación dunha organización instrumental especializada ao servizo do desenvolvemento do tecido empresarial propio do mercado cultural galego.

No seo da AGADIC incardinábanse outros organismos que estaban a funcionar como dinamizadores especializados por sectores das industrias galegas, creados antes desta data, e progresivamente fóronse incorporando novas iniciativas institucionais que focalizaban os seus esforzos noutras ramas culturais carentes de plataformas de apoio previas. Podemos mencionar os seguintes:

- Centro Dramático Galego, fundado en 1984 (http://www.centrodramatico.org/cdg/).

- Centro Coreográfico Galego, creado en 2006 (http://www.centrocoreografico.org/ccg/).

- O CGAI, Centro Galego de Artes da Imaxe, fundado en 1989 (http://www.cgai.org/), que centra as súas actividades na recuperación, catalogación, conservación, difusión e promoción do patrimonio audiovisual e fotográfico de Galiza.

- Galiciantunes "é a marca da promoción internacional da música galega, ideada como plataforma conxunta das institucións, empresas e asociacións profesionais do sector musical en Galicia" (http://www.galiciantunes.com/), creada en 2007. Conta co apoio da AGADIC e da AGEM, Asociación Galega de Empresas Musicais.

\footnotetext{
${ }^{10}$ Neste período de goberno ditáronse sete leis culturais, fronte á tónica xeral nos períodos precedentes de promulgar unha, fóra da situación excepcional da primeira lexislatura autonómica en que se aprobaran cinco (véxase Lage, Losada e Gómez 2012: 128).
} 
A actividade actual da Axencia divídese entre a canalización das axudas públicas entre as distintas especialidades do sector e un esforzo por crear sinerxias construtivas e redes de apoio entre todos os axentes implicados no desenvolvemento de proxectos culturais sostíbeis. En relación a este último punto cabe mencionar as iniciativas de traballo en rede promovidas desde a propia AGADIC que se substancian nas xa coñecidas Rede Galega de Teatros e Auditorios, Rede Galega de Salas e Rede Galega de Música ao Vivo. A estas propostas engádense outras actividades promovidas desde a Axencia, como a Feira Galega das Artes Escénicas, que xa cumpre 22 anos (hoxe denominada Galicia Escena PRO), o apoio institucional a plataformas profesionais, como acontece co sector das artes escénicas, onde funciona Galescena.info (http://www.galescena.info/), o mantemento dunha canle informativa sobre novas das industrias CanleTV (http://canletv.agadic.info/) e a participación noutras propostas do sector vindas de iniciativas privadas que reclaman atención pública.

\section{O IMPACTO DAS INDUSTRIAS CUL- TURAIS EN GALIZA}

As industrias culturais representan en Galiza un $2,3 \%$ do total do emprego, fronte ao $2,8 \%$ no conxunto do Estado e o 4,5\% da media europea (datos de 2013 ${ }^{11}$ ). A evolución que se pode advertir na produtividade do sector, medida en termos de emprego e rendibilidade económica amosan tanto un aumento evidente tras a fundación da AGADIC, como un descenso de beneficios provocado por efecto da crise económica até rexistrar datos inferiores aos anteriores a este contexto de recesión. Estes datos continúan unha evolución paralela aos contabilizados no resto do Estado, se ben non se advirten as flutuación negativas presentes en Galiza entre 2007-2008, período previo a que comenzase a funcionar a Axencia.

Tamén pode ser indicativa a evolución advertida na produtividade económica do sector, segundo as distintas ramas de actividade. Os valores absolutos recollidos até 2012 polo Instituto Galego de Estatística (IGE), contabilizados por miles de euros, evidencian

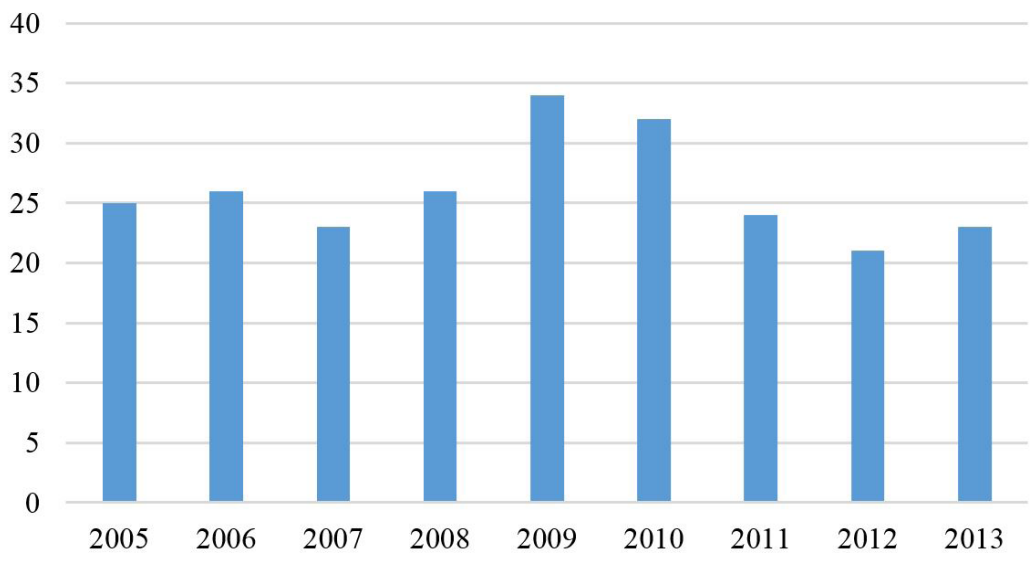

\begin{tabular}{l|l} 
ANO & $\mathrm{m} €$ \\
\hline 2005 & 25 \\
\hline 2006 & 26 \\
\hline 2007 & 23 \\
\hline 2008 & 26 \\
\hline 2009 & 34 \\
\hline 2010 & 32 \\
\hline 2011 & 24 \\
\hline 2012 & 21 \\
\hline 2013 & 23
\end{tabular}

Tabela 1. Emprego bruto en miles de euros (Galiza)

${ }^{11}$ Estatísticas do Ministerio de Cultura: http://www.mcu.es/culturabase/cgi/axi. As referencias a Europa foron tiradas do sitio oficial do Programa Media, da Comisión Europea: http://www.oficinamediaespana.eu/noticia.asp?p=la-comision-acoge-con-satisfaccion-la-aprobacion-del-programa-europa-creativa-por-el-parlamento-europeo (última consulta: 22/10/2014). 


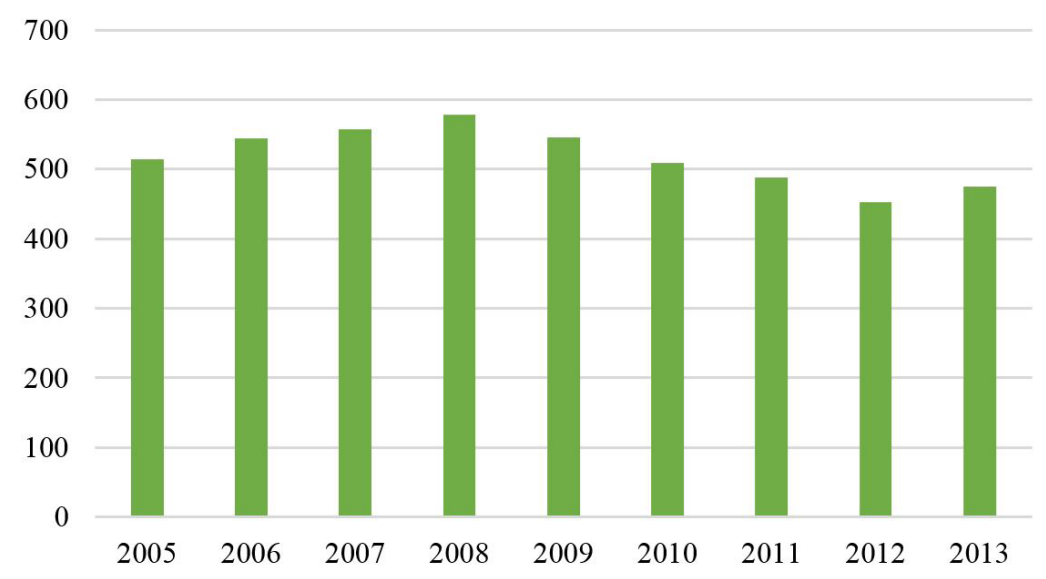

\begin{tabular}{l|l}
$\mathrm{ANO}$ & $\mathrm{m} €$ \\
\hline 2005 & 514 \\
\hline 2006 & 544 \\
\hline 2007 & 557 \\
\hline 2008 & 578 \\
\hline 2009 & 545 \\
\hline 2010 & 509 \\
\hline 2011 & 488 \\
\hline 2012 & 453 \\
\hline 2013 & 475
\end{tabular}

Tabela 2. Emprego bruto en miles de euros (España)

as flutuacións presentes nas distintas actividades, obviamente sensíbeis ao actual contexto económico de recesión, particularmente no eido das disciplinas audiovisuais (Tabela 3).

Con todo, os datos revelados nas últimas estatísticas contabilizadas en 2013 permiten advertir unha tímida recuperación no emprego do sector en todo o ámbito nacional. O paradoxo destes resultados reside en que as iniciativas de recuperación non proveñen dun maior investimento de gasto público na industria, senón da movilización interna do propio sector, que procura vías propias de sostibilidade e autonomía. A partida para gastos culturais dos Orzamentos Xerais do Estado de 2013 diminuíu nun $19,6 \%$ con respecto ao ano anterior $^{12}$. Esta situación evidencia, por tanto, que no seo da industria se está a producir un salto cualitativo cara a unha maior profesionalización e xeración de mecanismos de autoxestión.

\section{7. ÚLTIMAS INICIATIVAS DA INDUS- TRIA GALEGA}

A reacción da industria fronte á diminución do investimento público en cultura é a de procurar mecanismos internos cara a un maior aproveitamento dos recusos propios preexistentes, unha maior eficacia nas iniciativas, o mantemento de sinerxias positivas baseadas na creación de redes entre os profesionais do sector, o xurdimento de propostas cunha maior implicación da cidadanía, o deseño de estratexias que garantan a conservación e fidelidade do público e a integración nos proxectos das novas técnicas de comunicación tecnolóxica que axuden a acadar a constante actualización de contidos e o contacto permanente cos consumidores.

Bibliotecas, arquivos, museos e outras actividades culturais Edición de libros, periódicos e outras actividades editoriais Actividades cinematográficas, de vídeo, radio, televisión e edición musical Actividades de deseño, creacións artísticas e de espectáculos Actividades de fotografía Artes gráficas e reprodución de soportes gravados

\begin{tabular}{r|r|r|r}
$\mathbf{2 0 0 9}$ & $\mathbf{2 0 1 0}$ & $\mathbf{2 0 1 1}$ & $\mathbf{2 0 1 2}$ \\
\hline 67 & 133 & 158 & 180 \\
\hline 345 & 364 & 359 & 357 \\
\hline 440 & 386 & 401 & 387 \\
\hline 1307 & 1452 & 1411 & 1412 \\
\hline 582 & 542 & 559 & 543 \\
\hline 775 & 769 & 752 & 750
\end{tabular}

Tabela 3. Valores absolutos en miles de euros (datos do IGE)

\footnotetext{
12 Bustamante Ramírez (2013: 12); a modo de exemplo podemos indicar os gastos presupostados (en millóns de euros) para 2009: 1284; 2010: 1199; 2011: 1103,99; 2012: 897,52; 2013: 722.
} 
A modo de apuntamento podemos mencionar algunhas das tendencias advertidas no ámbito da nosa comunidade, que dan boa conta dos esforzos realizados pola industria para reaccionar fronte ás dificultades do actual contexto económico:

- Consolidación do entramado empresarial especializado por ramas de actividade. O exemplo paradigmático deste caso é o Clúster Audiovisual Galego, creado en 2003, unha das asociacións empresariais estratéxicas máis salientábeis no contexto da economía de Galiza, que sentou precedente con respecto á materia audiovisual mesmo para o resto de España. Tamén cómpre mencionar o Clúster do Produto Gráfico e do Libro Galego, que comezou a funcionar en 2007.

- Xurdimento de novas plataformas de traballo con espazos dedicados ao sector. Neste punto convén mencionar o espazo de coworking para iniciativas culturais aberto na Cidade da Cultura, ao que se engade unha convocatoria pública (desde 2013) para premiar proxectos culturais que queiran empregar esta sede como incubadora ${ }^{13}$.

- Profesionalización do sector: consolidación da figura do xestor cultural e aparición en 2008 da primeira Asociación Galega de Profesionais da Xestión Cultural, coa finalidade de crear e manter redes de contacto e apoio cualificado aos sectores que o soliciten, alén de actividades formativas e consultoría (http://xestoresculturais.org/es/).

- Un maior e consolidado asociacionismo profesional por especialidades do sector. Citaremos os principais: Asociación Galega de Editores (AGE, 1986 http://www.editoresgalegos.org/); Asociación Galega de Empresas de Artes Escénicas (2002 http://www.escenagalega.blogspot.com.es/); Asociación Galega de Empresas Musicais (AGEM, 2007 http://www.agem-musica.com/); Asociación Galega de Produtoras Fonográficas (Agaphono, 2002), Empresas Galegas adicadas a Internet e ás Novas Tecnoloxías (Eganet, 2000 http://www.eganet.org/); Asociación Galega de Produtoras Independentes (Agapi, 1994 http://www.agapi.org/).

- Realización de eventos e xestión de iniciativas que tratan de dinamizar o tecido da industria cultural galega, como Culturgal (http://culturgal.com/), Feira das Industrias Culturais creada en 2007 e con convocatorias regulares desde 2010; propostas que tratan de tender lazos co norte de Portugal, como foi o caso de Creativa, que funcionou entre 2009 e 2010; MICAtlántica, Mercado das Industrias Culturais, cuxa primeira edición foi en 2013 (http://www.micatlantica. org/idioma/2).

Estes datos xerais reflicten unha tendencia mantida no sector como estratexia na procura de sostibilidade e autonomía financeira. A isto engádense novas iniciativas privadas que aproveitan espazos de mercado na procura dunha especialización que garanta a súa viabilidade. En moitas ocasións, esa especialidade baséase nunha ausencia de oferta previa no noso ámbito territorial ou nas particularidades da nosa cultura. Nese sentido, Galiza conta con recursos culturais abondos que evidencian unha gran riqueza, pluralidade e diversidade capaces de desenvolver, malia a adversidade do contexto socio-político que nos antecedeu e do influxo da recesión aínda presente, unha cultura con identidade propia capaz de amparar proxectos plenamente autónomos e factíbeis.

\section{REFERENCIAS BIBLIOGRÁFICAS}

BuSTAMANTE RAmírez, Enrique (2013): España: la cultura en tiempo de crisis. Fuentes financieras y políticas públicas. Madrid: Fundación Alternativas.

FERNÁNDEZ FreiXANES, Víctor (2010): “As industrias culturais na construción dun discurso social”, en V. Fernández Freixanes e A. Meixide (eds.), O capital da cultura. Unha achega ás industrias culturais de Galicia. Santiago de Compostela: Fundación Caixa Galicia, pp. 13-27.

\footnotetext{
${ }^{13}$ https://www.cidadedacultura.org/gl/info/coworking-emprende-cultura-gaias.
} 
Getino, Octavio (2001): “Aproximación a un estudio de las Industrias Culturales en el Mercosur (Incidencia económica, social y cultural para la integración regional)", en Seminario Internacional "Importancia y Proyección del Mercosur Cultural con miras a la Integración" Santiago de Chile, 3, 4 y 5 de mayo de 2001 (dispoñíbel en: http://www.oei.es/cultura2/getino.htm).

Lage, Xesús, Antón Losada e Marta Gómez (2012): "La política cultural en la comunidad autónoma gallega: de la dependencia a la autonomía", RIPS. Revista de investigaciones políticas y sociológicas 3, pp. 115-148 (dispoñíbel en: http://www.usc.es/revistas/index.php/rips/article/ viewFile/1021/954).

ReYes, Ramón (dir.) (2009): Diccionario Crítico de las Ciencias Sociales. Madrid: Universidad Complutense (dispoñíbel en: http://pendientedemigracion.ucm.es/info /eurotheo/diccionario/ index b.html)

Ruano, Soledad (2007): "Las Industrias Culturales, el Negocio de la Era Digital”, Razón y Palabra 56 (dipoñíbel en: http://www.razonypalabra.org.mx/anteriores/n56/sruano.html).

Zallo Elguezabal, Ramón (1988): Economía de la comunicación y la cultura. Torrejón de Ardoz: Akal.

(2007): "La economía de la cultura (y de la comunicación) como objeto de estudio", Zer. Revista de estudios de comunicación 22, pp. 215-234 (dispoñíbel en: http://www.ehu.es/zer/ hemeroteca/). 